\title{
Molecular background of the regional lymph node metastasis of gastric cancer (Review)
}

\author{
TONG ZHU ${ }^{1 *}$, XUEQIAN HU ${ }^{2 *}$, PINKANG WEI $^{3}$ and GUANGZHI SHAN ${ }^{2}$ \\ ${ }^{1}$ Department of Oncology, Changzheng Hospital, The Second Military Medical University, Shanghai 200003; \\ ${ }^{2}$ Department of Oncology, Ningbo Municipal Hospital of Traditional Chinese Medicine, Ningbo, \\ Zhejiang 315000; ${ }^{3}$ Department of Traditional Chinese Medicine, Changzheng Hospital, \\ The Second Military Medical University, Shanghai 200003, P.R. China
}

Received November 13, 2015; Accepted December 4, 2017

DOI: $10.3892 / \mathrm{ol} .2018 .7813$

\begin{abstract}
Gastric cancer (GC) is one of the deadliest types of cancer in the world. Lymph node (LN) metastasis is a complex and malignant behavior of $\mathrm{GC}$, involving a sequence of biological processes, including decreased adherence to adjacent cells, extracellular matrix (ECM) degradation and lymphatic channel permeation. LN metastasis is directly associated with the treatment response, local recurrence and long-term survival of patients with GC. Therefore, the molecular mechanisms of $\mathrm{LN}$ metastasis in GC development require further investigation. Recently, a large number of clinical studies have focused on the molecular mechanisms and biological markers of tumor invasion and metastasis. However, few articles have broadly summarized LN metastasis in GC, and the molecular mechanisms of LN metastasis are not yet fully understood. In the present review, the molecular mechanisms of LN metastasis in GC will be discussed, including the following aspects: Cell adhesion and movement, ECM degradation, new vessel formation, and molecular pattern differences between metastatic LNs and the primary tumor. This review may lead to a better understanding of LN metastasis in GC, and the identification of new diagnostic markers.
\end{abstract}

Correspondence to: Dr Pinkang Wei, Department of Traditional Chinese Medicine, Changzheng Hospital, The Second Military Medical University, 415 Fengyang Road, Shanghai 200003, P.R. China

E-mail: weipinkang@aliyun.com

Dr Guangzhi Shan, Department of Oncology, Ningbo Municipal Hospital of Traditional Chinese Medicine, 819 North Liyuan Road, Haishu, Ningbo, Zhejiang 315000, P.R. China

E-mail: shanguangzhi@aliyun.com

*Contributed equally

Key words: gastric cancer, lymph node metastasis, molecular mechanism, extracellular matrix, lymphangiogenesis, chemokines

\section{Contents}

1. Introduction

2. Degradation of the ECM

3. Lymphangiogenesis and metastasis

4. Alterations in gene expression in metastatic LNs

5. Other mechanisms

6. Conclusions

\section{Introduction}

Gastric cancer (GC), one of the most common types of cancer(1), has a high mortality rate, which is predominantly caused by its delayed diagnosis due to the absence of early-stage clinical symptoms (2). A typical malignant behavior of GC is lymph node (LN) metastasis. The majority of epithelial cancers first spread through the lymph vessels into the draining LNs and gain metastatic development (3). The detection of metastasis in the sentinel LNs is often associated with adjuvant therapy decisions and has major prognostic implications for patients $(4,5)$.

Despite their clinical importance, the mechanisms of LN metastasis have yet to be completely characterized. LN metastasis is complicated and involves a sequence of biological processes: The primary tumor cells persistently proliferate, and separate from the adjacent cells and the basement membrane; the extracellular matrix (ECM) is degraded; the tumor cells permeate into the lymphatic channels, and so forth. In recent years, gene expression studies have been performed to detect specific molecular signatures for LN metastases.

At present, a challenge for anti-cancer strategies is the control of metastasis. For this reason, it is essential to explore the regulatory mechanisms of metastasis to aid the identification of therapies to improve the survival rate for cancer patients. In this article, relevant studies regarding the molecular mechanisms of the lymphatic metastasis of GC will be reviewed and summarized (Table I).

\section{Degradation of the ECM}

Cancer cells invade the surrounding stroma, subsequent to passing through the epithelial basement membrane, during 
Table I. Molecules associated with lymph node metastasis in gastric cancer.

Classification

Degradation of the extracellular matrix

Lymphangiogenesis

Chemokines and cell adhesion molecules Others
Associated molecules
Matrix metalloproteinases, tissue inhibitors of metalloproteinases, ADAM
metallopeptidases

Vascular endothelial growth factor, platelet-derived growth factor-BB, insulin-like growth factor-1, etc.

C-C motif chemokine receptor 7, integrins, E-cadherin, etc.

Annexin A1, zinc finger protein 139, c-MET, etc. metastasis. This process includes two crucial mechanisms: Reduced cell-cell adhesion and ECM degradation (6). ECM degradation is determined by the activity of various proteolytic enzymes, particularly Matrix metalloproteinases (MMPs) (7). In humans, the MMP family, which contains 24 zinc-dependent endopeptidases, participates in tumor cell invasion and metastasis by degrading collagen types IV and $\mathrm{V}$, components of the ECM (8). MMPs are usually relatively inactive, and can be activated when tissues are undergoing repair or remodeling, or in disease or inflammation (9). It has been reported that repressing the expression of certain MMPs is associated with increased survival and favorable prognosis in GC patients (10-12).

MMPs can be specifically regulated by tissue inhibitors of metalloproteinases (TIMPs). The balance between MMPs and TIMPs maintains the integrity of the ECM. During tumor metastasis, the imbalance of MMPs and TIMPs leads to ECM degradation (13,14). TIMP-1 is a major MMP inhibitor; however, it has a complicated role in tumor invasion and metastasis. In some cases, its function seems to be paradoxical: Increased MMP activity promotes tumor progression, while high levels of TIMP-1 are expected to inhibit tumor progression. For example, a previous study indicated that the increased expression of TIMP-1 in GC plasma or tumor tissue was strongly associated with a poor patient outcome $(\mathrm{P}<0.001)(15)$. In the study, the authors observed that TIMP-3 protein expression was remarkably downregulated in primary GC tissues, which was associated with the tumor stage and metastasis. Other studies demonstrated that the methylation status of TIMP-3 was significantly associated with LN metastasis, histological differentiation and the clinical stage (16-19) (Table II).

ADAM metallopeptidases share the metalloproteinase domain with MMPs, and are important in ECM degradation (20). A number of clinical studies $(21,22)$ have demonstrated that MMP and ADAM activity are associated with poor cancer outcomes. The upregulation of ADAMs has been observed in GC, and has been demonstrated to produce marked effects on tumor development and metastasis. The MMP family of enzymes has been a focus of GC study, and MMP-specific inhibitors could potentially interrupt tumor progression.

\section{Lymphangiogenesis and metastasis}

Lymphatic vessel proliferation is frequently observed in GC tissue, allowing tumor cells to permeate into the lymphatic channels. Lymphangiogenesis is the formation of lymphatic vessels within healthy tissues, and the similar process in carcinogenesis (23). Vascular endothelial growth factor (VEGF) is a key factor in tumor lymphangiogenesis and metastasis $(24,25)$. The increased expression of VEGF-C is associated with positive LN status and higher lymphatic vascular density, indicating its potential dual role in lymphatic vessel invasion and lymphangiogenesis (26). It has also been proposed that VEGF-C expressed by tumors interacts with the lymphatic endothelium, leading to its enlargement (27). VEGF-D, which is highly homologous to VEGF-C, induces lymphangiogenesis in tumor tissue and tumor cell diffusion to regional LNs (28). Previous clinical studies have demonstrated that bevacizumab, a humanized monoclonal antibody against VEGF, is clinically effective against GC (29-31). In a phase II study, Shah et al (32) evaluated bevacizumab with chemotherapy in 44 eligible cancer patients $(\mathrm{GC}, \mathrm{n}=22$; cancer of the esophagogastric junction, $n=20$; esophageal cancer, $n=2$ ). The response rate was $67 \%$ for the 39 patients with measurable disease.

Studies on cervical and gastric tumors have revealed a strong association between lymphatic vessel density (LVD), and LN metastasis and prognosis $(33,34)$ (Table II). In addition to the VEGF family, other mediators are also involved in lymphangiogenesis, including platelet-derived growth factor-BB (35), insulin-like growth factor 1 and -2 (36), fibroblast growth factor $2(37,38)$, hepatocyte growth factor (39) andangiopoietin-2 (40). The effects of these factors in GC require further investigation.

Chemokines are small secreted proteins that can enter inflammatory sites and secondary lymphoid organs via leukocyte recruitment. Chemokines and chemokine receptors function in a range of physiological processes, including cancer $(41,42)$. In GC, CXC-chemokine receptor (CXCR) CXCR4 and CXCR2 were highly expressed in cancer tissues and predicted advanced tumor stage and poorer overall survival $(43,44)$. C-C motif chemokine receptor 7 (CCR7) is a $\mathrm{G}$ protein-coupled receptor preferentially expressed on naive $\mathrm{T}$ cells and mature dendritic cells (45). A meta-analysis which included 1,697 participants with GC indicated that increased CCR7 expression was associated with negative clinicopathological prognostic factors including deeper tumor invasion and predicted a worse long-term survival outcome (46). The possible underlying molecular mechanism is that CCR7 contributes to TGF- $\beta 1$-induced epithelial-mesenchymal transition (EMT), facilitating lymph node metastasis in patients with gastric cancer $(47,48)$. Therefore CCR7 may potentially serve as a novel prognostic indicator and a potential target for gastric cancer therapy. At present, clinical trials of monoclonal 


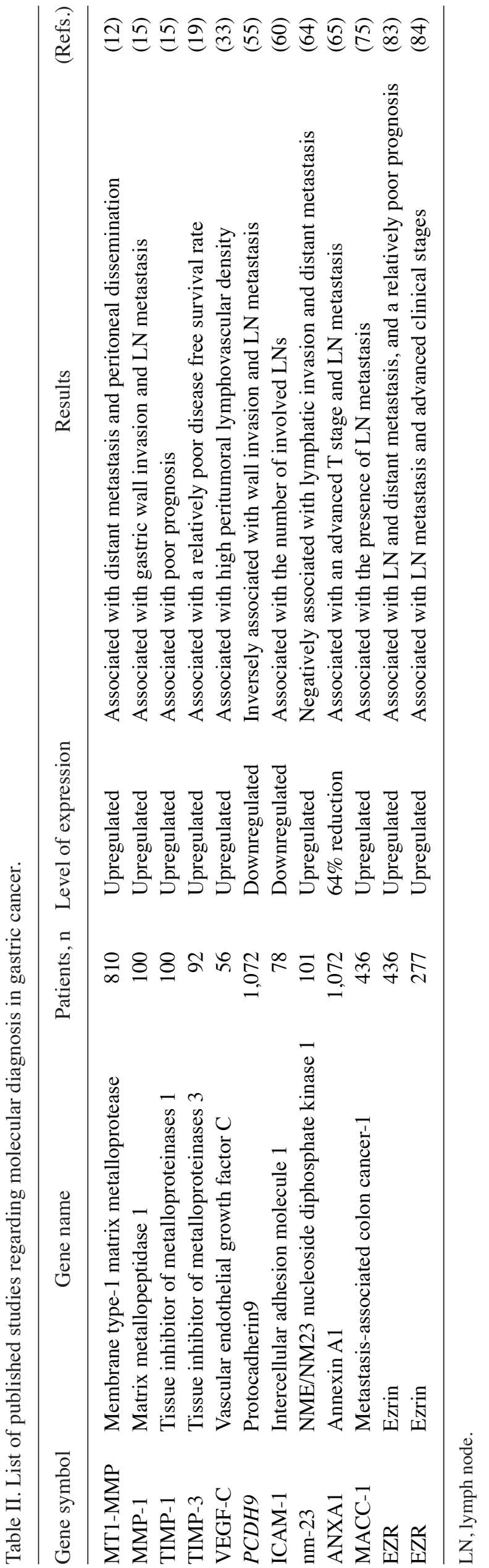

antibodies against CXCR4, CCR2 and CCR4 for cancer treatment are being conducted (49).

As the expression of cell adhesion molecules (CAMs) decreases, metastatic potential increases $(50,51)$. CAMs, glycoproteins on the cell surface, are divided into four families: Lntegrins, selectins, cadherins and immunoglobulin superfamily CAMs. Integrins, the principal adhesion receptors of the ECM, are vital for multicellular organisms (52). A strong association has been identified between serum integrin $\beta 1$ content and tumor staging, LN metastasis and distant metastasis (53). E-cadherin (E-cad) mediates calcium-dependent cell-cell adhesion (54). A recent study has demonstrated that abnormally expressed protocadherin 9 is significantly associated with LN metastasis in patients with GC (55) (Table II). Selectins are adhesion molecules that mediate the initial leukocyte binding to the microvascular endothelium (56). E-Selectin levels were elevated in patients with GC with peritoneal metastasis and associated with poorer prognosis (57). P-selectin and L-selectin act as mediators for the interaction between platelets and leukocytes with circulating tumor cells during tumor dissemination (58). Intercellular adhesion molecule-1 (ICAM-1) can prevent cancer cells from being recognized and attacked by immunocytes, thus accelerating metastasis (59). Yashiro et al (60) suggested that ICAM-1 facilitates GC cell adhesion to immune cells, leading to immune tolerance (Table II). However, other studies have demonstrated an association between the serum levels of circulating ICAM-1 and GC tumor progression, with higher levels indicating a worse prognosis $(53,61,62)$. On account of the contradictory results in these studies, ICAM-1 has not yet been established as a prognostic marker in GC.

\section{Alterations in gene expression in metastatic LNs}

Previous studies have demonstrated that the molecular patterns in metastatic LNs may differ from those in the primary tumor. It was identified in early research that the expression of a metastasis suppressor gene, NME/NM23 nucleoside diphosphate kinase 1 , was different between primary and metastatic lesions in GC $(63,64)$ (Table II). In our previous study, Annexin A (ANXA) 1 expression was revealed to be significantly increased in metastatic LNs compared with primary GC tumors or normal gastric tissue in (65) (Table II). Li et al (66) demonstrated that zinc finger protein 139 (ZNF139) regulated ANXA1 and ANXA5 expression, and promoted the LN metastasis of GC. ZNF139 is associated with multidrug resistance, and may promote GC invasion and metastasis $(67,68)$.

Another study identified that primary tumors and metastatic LNs expressed a variable level of sialyl-related antigen in GC (69). This may have been caused by: i) Cancer cells producing sialyl-related antigens in the LNs once migrated from the primary tumor lesion; ii) in tumor progression, cancer cells that were unable to produce these antigens in the primary lesion obtaining the ability to produce sialyl-related antigens in the LNs; and iii) during the metastasis to LNs, cancer cells that could produce sialyl-related antigens in the primary lesion losing the ability to produce these antigens (69).

Connexins (Cxs) serve an important role in Gap junctions, which occur in most epithelial tissues (70). Mounting evidence suggests that $\mathrm{Cx} 43$ participates in tumor metastasis by 
interacting with cell adhesion-associated proteins, including E-cad (71). The expression of Cx43 and E-cadherin was significantly increased in matched metastatic lymph nodes (MLNs) compared with primary gastric tumors. This may contribute to the efficient lymph node metastasis identified in gastric cancer (72).

These studies collectively suggest there is heterogeneity in gene expression between the primary tumor and LN metastases. In conclusion, considering gene status in the primary tumor alone may not be accurate enough to determine a suitable strategy for treatment.

\section{Other mechanisms}

MET encodes a tyrosine kinase receptor that is associated with cancer progression (73,74). In a recent study, the amplification of MET was observed in patients with GC, and was indicative of the likelihood of tumor invasion and LN metastasis (75). Furthermore, the role of MET gene amplification in c-MET overexpression and MET/hepatocyte growth factor (HGF) pathway activation have been generally recognized (76). The physiological activation of c-MET is induced by its natural ligand, HGF (77). The activation of c-MET by paracrine HGF is pivotal in GC pathogenesis (78). Metastasis-associated colon cancer-1 (MACC-1), a novel key regulator of HGF/MET signaling, can induce MET expression and facilitate tumor invasion and metastasis (75). It has been demonstrated that MACC-1 expression is correlated with c-Met expression in GC (79). Furthermore, silencing MACC-1 can inhibit VEGF-C/VEGF-D expression and thus inhibit lymphangiogenesis (80).

The cytoskeletal protein Ezrin, a member of the Ezrin-Radixin-Moesin family, functions as a molecular cross linker between actin filaments and proteins anchored in the cell membrane. Ezrin participates in various cellular processes relevant to aggressive tumor behavior and various phases of tumor metastasis $(81,82)$. The immunohistochemical results from the analysis of $436 \mathrm{GC}$ samples demonstrated that high Ezrin expression in GC lesions was associated with LN and distant metastasis $(83,84)$ (Table II).

\section{Conclusions}

GC is one of the deadliest types of cancer worldwide, with only a 5-20\% 5-year survival rate in China (85). The prognosis for curative resection is unsatisfactory due to a high local recurrence rate, and early LN and systemic metastasis. Hence, it is vital to further investigate the molecular mechanisms in GC progression and identify new diagnostic markers. GC pathogenesis is a complicated process involving diverse alterations to genes and molecules, including the activation of oncogenes, the inactivation of tumor suppressor genes, and the dysregulation of the cell cycle (86). A large number of clinical studies have been performed regarding the molecular mechanisms and biological markers associated with GC cell invasion and metastasis $(87,88)$. However, the molecular mechanisms of GC metastasis have yet to be completely characterized.

In the present review, the molecular mechanisms of GC LN metastasis have been discussed, including the following aspects: Cell adhesion and movement, ECM degradation, new vessel formation, and molecular pattern differences between metastatic LNs and the primary tumor. In the future, research in this area should consider the molecular markers expressed specifically on metastatic LNs, to allow the detection of whether LNs are involved after surgery. Due to the complexity of the molecular mechanisms, the roles of a number of molecules remain controversial. Therefore, large-scale basic research and a large number of clinical specimens are necessary for developing a further understanding, and the screening of relevant molecules. Novel antitumor drugs targeting the newly identified molecular markers can then be developed to prevent GC metastasis at an early stage.

\section{References}

1. Torre LA, Bray F, Siegel RL, Ferlay J, Lortet-Tieulent J and Jemal A: Global cancer statistics, 2012. CA Cancer J Clin 65: 87-108, 2015.

2. Lianos GD, Rausei S, Ruspi L, Galli F, Mangano A, Roukos DH, Dionigi $\mathrm{G}$ and Boni L: Laparoscopic gastrectomy for gastric cancer: Current evidences. Int J Surg 12: 1369-1373, 2014.

3. de Boer M, van Dijck JA, Bult P, Borm GF and Heijnen VC: Breast cancer prognosis and occult lymph node metastases, isolated tumor cells, and micrometastases. J Natl Cancer Inst 102: 410-425, 2010.

4. Deng JY and Liang H: Clinical significance of lymph node metastasis in gastric cancer. World J Gastroenterol 20: 3967-3975, 2014.

5. Velho S, Fernandes MS, Leite M, Figueiredo C and Seruca R: Causes and consequences of microsatellite instability in gastric carcinogenesis. World J Gastroenterol 20: 16433-16442, 2014.

6. Paz H, Pathak N and Yang J: Invading one step at a time: The role of invadopodia in tumor metastasis. Oncogene 33: 4193-4202, 2014.

7. Egeblad M and Werb Z: New functions for the matrix metalloproteinases in cancer progression. Nat Rev Cancer 3: 161-174, 2002.

8. de la Peña S, Sampieri CL, Ochoa-Lara M, León-Córdoba K and Remes-Troche JM: Expression of the matrix metalloproteases 2, 14, 24 and 25 and tissue inhibitor 3 as potential molecular markers in advanced human gastric cancer. Dis Markers 2014: 285906, 2014.

9. Lu PF, Weaver VM and Werb Z: The extracellular matrix: A dynamic niche in cancer progression. J Cell Biol 196: 395-406, 2012.

10. Dey S, Ghosh N, Saha D, Kesh K, Gupta A and Swarnakar S: Matrix metalloproteinase-1 (MMP-1) promoter polymorphisms are well linked with lower stomach tumor formation in eastern Indian population. PLoS One 9: e88040, 2014.

11. Shen WS, Xi HQ, Wei B and Chen L: The prognostic role of matrix metalloproteinase 2 in gastric cancer: A systematic review with meta-analysis. J Cancer Res Clin Oncol 140: 1003-1009, 2014.

12. Mimori K, Fukagawa T, Kosaka Y, Ishikawa K, Iwatsuki M, Yokobori T, Hirasaki S, Takatsuno Y, Sakashita H, Ishii H, et al: A large-scale study of MT1-MMP as a marker for isolated tumor cells in peripheral blood and bone marrow in gastric cancer cases. Ann Surg Oncol 15: 2934-2942, 2008.

13. Ninomiya T, Yoon S, Nagano H, Kumon Y, Seo Y, Kasuga M, Yano Y, Nakaji M and Hayashi Y: Significance of serum matrix metalloproteinases and their inhibitors on the antifibrogenetic effect of interferon-alfa in chronic hepatitis $\mathrm{C}$ patients. Intervirology 44: 227-231, 2001.

14. Nuttall RK, Sampieri CL, Pennington CJ, Gill SE, Schultz GA and Edwards DR: Expression analysis of the entire MMP and TIMP gene families during mouse tissue development. FEBS Lett 563: 129-134, 2004.

15. Kemik O, Kemik AS, Sümer A, Dulger AC, Adas M, Begenik H, Hasirci I, Yilmaz O, Purisa S, Kisli E, et al: Levels of matrix metalloproteinase-1 and tissue inhibitors of metalloproteinase-1 in gastric cancer. World J Gastroenterol 17: 2109-2112, 2011.

16. Menghini R, Menini S, Amoruso R, Fiorentino L, Casagrande V, Marzano V, Tornei F, Bertucci P, Iacobini C, Serino M, et al: Tissue inhibitor of metalloproteinase 3 deficiency causes hepatic steatosis and adipose tissue inflammation in mice. Gastroenterology 136: 663-672.e4, 2009. 
17. Yoo EJ, Park SY, Cho NY, Kim N, Lee HS and Kang GH: Helicobacter pylori-infection-associated $\mathrm{CpG}$ island hypermethylation in the stomach and its possible association with polycomb repressive marks. Virchows Arch 452: 514-524, 2008.

18. Shin SH, Park SY, Ko JS, Kim N and Kang GH: Aberrant $\mathrm{CpG}$ island hypermethylation in pediatric gastric mucosa in association with Helicobacter pylori infection. Arch Pathol Lab Med 135: 759-765, 2011.

19. Yu JL, Lv P, Han J, Zhu X, Hong LL, Zhu WY, Wang XB, Wu YC, Li P and Ling ZQ: Methylated TIMP-3 DNA in body fluids is an independent prognostic factor for gastric cancer. Arch Pathol Lab Med 138: 1466-1473, 2014.

20. Rocks N, Paulissen G, El Hour M, Quesada F, Crahay C, Gueders M, Foidart JM, Noel A and Cataldo D: Emerging roles of ADAM and ADAMTS metalloproteinases in cancer. Biochimie 90: 369-379, 2008.

21. Kim KE, Song H, Hahm C, Yoon SY, Park S, Lee HR, Hur DY, Kim T, Kim CH, Bang SI, et al: Expression of ADAM33 is a novel regulatory mechanism in IL-18-secreted process in gastric cancer. J Immunol 182: 3548-3555, 2009.

22. Carl-McGrath S,Lendeckel U, Ebert M, Roessner A and Röcken C: The disintegrin-metalloproteinases ADAM9, ADAM12, and ADAM15 are upregulated in gastric cancer. Int J Oncol 26: 17-24, 2005.

23. Folkman J: The role of angiogenesis in tumor growth. Semin Cancer Biol 3: 65-71, 1992.

24. Vermeulen PB, van Golen KL and Dirix LY: Angiogenesis, lymphangiogenesis, growth pattern, and tumor emboli in inflammatory breast cancer: A review of the current knowledge. Cancer 116 (11 Suppl): S2748-S2754, 2010.

25. Raica M and Ribatti D: Targeting tumor lymphangiogenesis: An update. Curr Med Chem 17: 698-708, 2010.

26. Kostis G, Ioannis L, Helen K and Helen P: The expression of vascular endothelial growth factor-C correlates with lymphatic microvessel density and lymph node metastasis in prostate carcinoma: An immunohistochemical study. Urol Ann 6: 224-230, 2014

27. Hoshida T, Isaka N, Hagendoorn J, di Tomaso E, Chen YL, Pytowski B, Fukumura D, Padera TP and Jain RK: Imaging steps of lymphatic metastasis reveals that vascular endothelial growth factor-C increases metastasis by increasing delivery of cancer cells to lymph nodes: Therapeutic implications. Cancer Res 66: 8065-8075, 2006

28. Harris NC, Davydova N, Roufail S, Paquet-Fifield S, Paavonen K, Karnezis T, Zhang YF, Sato T, Rothacker J, Nice EC, et al: The propeptides of VEGF-D determine heparin binding, receptor heterodimerization, and effects on tumor biology. J Biol Chem 288 8176-8186, 2013.

29. Aoyagi K, Kouhuji K, Miyagi M, Kizaki J, Isobe T, Hashimoto K and Shirouzu K: Molecular targeting therapy using bevacizumab for peritoneal metastasis from gastric cancer. World J Crit Care Med 2: 48-55, 2013

30. Shah MA, Jhawer M, Ilson DH, Lefkowitz RA, Robinson E, Capanu M and Kelsen DP: Phase II study of modified docetaxel, cisplatin, and fluorouracil with bevacizumab in patients with metastatic gastroesophageal adenocarcinoma. J Clin Oncol 29: 868-874, 2011.

31. Ohtsu A, Shah MA, Van Cutsem E, Rha SY, Sawaki A, Park SR, Lim HY, Yamada Y, Wu J, Langer B, et al: Bevacizumab in combination with chemotherapy as first-line therapy in advanced gastric cancer: A randomized, double-blind, placebo-controlled phase III study. J Clin Oncol 29: 3968-3976, 2011.

32. Shah MA, Ramanathan RK, Ilson DH, Levnor A, D'Adamo D, O'Reilly E, Tse A, Trocola R, Schwartz L, Capanu M, et al: Multicenter phase II study of irinotecan, cisplatin and bevacizumab in patients with metastatic gastric or gastroesophageal junction adenocarcinoma. J Clin Oncol 24: 5201-5206, 2006.

33. Gou HF, Chen XC, Zhu J, Jiang M, Yang Y, Cao D and Hou M: Expressions of COX-2 and VEGF-C in gastric cancer: Correlations with lymphangiogenesis and prognostic implications. J Exp Clin Cancer Res 30: 14, 2011.

34. Botting SK, Fouad H, Elwell K, Rampy BA, Salama SA, Freeman DH and Diaz-Arrastia CR: Prognostic significance of peritumoral lymphatic vessel density and vascular endothelial growth factor receptor 3 in invasive squamous cell cervical cancer. Transl Oncol 3: 170-175, 2010.

35. Cao R, Björndahl MA, Religa P, Clasper S, Garvin S, Galter D, Meister B, Ikomi F, Tritsaris K, Dissing S, et al: PDGF-BB induces intratumoral lymphangiogenesis and promotes lymphatic metastasis. Cancer Cell 6: 333-345, 2004.
36. Björndahl M, Cao R, Nissen LJ, Clasper S, Johnson LA, Xue Y, Zhou Z, Jackson D, Hansen A and Cao YH: Insulin-like growth factors 1 and 2 induce lymphangiogenesis in vivo. Proc Natl Acad Sci USA 102: 15593-15598, 2005.

37. Platonova N, Miquel G, Regenfuss B, Taouji S, Cursiefen S, Chevet $\mathrm{E}$ and Bikfalvi A: Evidence for the interaction of fibroblast growth factor-2 with the lymphatic endothelial cell marker LYVE-1. Blood 121: 1229-1237, 2013.

38. Schulz MM, Reisen F, Zgraggen S, Fischer S, Yuen D, Kang GJ, Chen L, Schneider G and Detmar M: Phenotype-based high-content chemical library screening identifies statins as inhibitors of in vivo lymphangiogenesis. Proc Natl Acad Sci USA 109: E2665-E2674, 2012.

39. Cao R, Björndahl MA, Gallego MI, Chen S, Religa P, Hansen AJ and Cao Y: Hepatocyte growth factor is a lymphangiogenic factor with an indirect mechanism of action. Blood 107: 3531-3536, 2006.

40. Holopainen T, Saharinen P, D'Amico G, Lampinen A, Eklund L, Sormunen R, Anisimov A, Zarkada G, Lohela M, Heloterä H, et al: Effects of angiopoietin-2-blocking antibody on endothelial cell-cell junctions and lung metastasis. J Natl Cancer Inst 104: 461-475, 2012.

41. Sumida H, Yanagida K, Kita Y, Abe J, Matsushima K, Nakamura M, Ishii S, Sato S and Shimizu T: Interplay between CXCR2 and BLT1 facilitates neutrophil infiltration and resultant keratinocyte activation in a murine model of imiquimod-induced psoriasis. J Immunol 192: 4361-4369, 2014.

42. Chiba F, Soda K, Yamada S, Tokutake Y, Chohnan S and Konishi F: The importance of tissue environment surrounding the tumor on the development of cancer cachexia. Int J Oncol 44: 177-186, 2014.

43. Cheng WL, Wang CS, Huang YH, Tsai MM, Liang Y and Lin KH: Overexpression of CXCL1 and its receptor CXCR2 promote tumor invasion in gastric cancer. Ann Oncol 22: 2267-2276, 2011.

44. Xiang Z, Zhou ZJ, Xia GK, Zhang XH, Wei ZW, Zhu JT, Yu J, Chen W, He Y, Schwarz RE, et al: A positive crosstalk between CXCR4 and CXCR2 promotes gastric cancer metastasis. Oncogene 34: 5122-5133, 2015.

45. Itakura M, Tokuda A, Kimura H, Nagai S, Yoneyama $H$, Onai N, Ishikawa S, Kuriyama T and Matsushima K: Blockade of secondary lymphoid tissue chemokine exacerbatesPropionibacterium acnes-induced acute lung inflammation. J Immunol 3: 2071-2079, 2001.

46. Du P, Liu Y, Ren H, Zhao J, Zhang X, Patel R, Hu C, Gan J and Huang G: Expression of chemokine receptor CCR7 is a negative prognostic factor for patients with gastric cancer: A meta-analysis. Gastric Cancer 20: 235-245, 2017.

47. Ma H, Gao L, Li S, Qin J, Chen L, Liu X, Xu P, Wang F, Xiao H, Zhou S, et al: CCR7 enhances TGF- $\beta 1$-induced epithelial-mesenchymal transition and is associated with lymph node metastasis and poor overall survival in gastric cancer. Oncotarget 6: 24348-24360, 2015.

48. Zhang J, Zhou Y and Yang Y: CCR7 pathway induces epithelial-mesenchymal transition through up-regulation of Snail signaling in gastric cancer. Med Oncol 32: 467, 2015.

49. Vela M, Aris M, Llorente M, Garcia-Sanz JA and Kremer L: Chemokine receptor-specific antibodies in cancer immunotherapy: Achievements and challenges. Front Immunol 6: 12, 2015.

50. Le Bras GF, Taubenslag KJ and Andl CD: The regulation of cell-cell adhesion during epithelial-mesenchymal transition, motility and tumor progression. Cell Adh Migr 6: 365-373, 2012.

51. Zhong X and Rescorla FJ: Cell surface adhesion molecules and adhesion-initiated signaling: Understanding of anoikis resistance mechanisms and therapeutic opportunities. Cell Signal 24: 393-401, 2012

52. Kim YJ, Borsig L, Han HL, Varki NM and Varki A: Distinct selectin ligands on colon carcinoma mucins can mediate pathological interactions among platelets, leukocytes and endothelium. Am J Pathol 155: 461-472, 1999.

53. Ke JJ, Shao QS and Ling ZQ: Expression of E-selectin, integrin beta 1 and immunoglobulin superfamily member in human gastric carcinoma cells and its clinicopathologic significance. World J Gastroenterol 12: 3609-3611, 2006.

54. Liu Y, Zhao J, Zhang PY, Zhang Y, Sun SY, Yu SY and Xi QS: MicroRNA-10b targets E-cadherin and modulates breast cancer metastasis. Med Sci Monit 18: BR299-BR308, 2012

55. Chen Y, Xiang H, Zhang Y, Wang J and Yu G: Loss of PCDH9 is associated with the differentiation of tumor cells and metastasis and predicts poor survival in gastric cancer. Clin Exp Metastasis 32: 417-428, 2015 
56. Bevilacqua MP and Nelson RM: Selectins. J Clin Invest 91 379-387, 1993.

57. Benekli M, Güllü IH, Tekuzman G, Savas MC, Hayran M, Hasçelik $\mathrm{G}$ and Firat D: Circulating intercellular adhesion molecule-1 and E-selectin levels in gastric cancer. Br J Cancer 78 267-271, 1998.

58. Borsig L, Wong R, Hynes RO, Varki NM and Varki A: Synergistic effects of L- and P-selectin in facilitating tumor metastasis can involve non-mucin ligands and implicate leukocytes as enhancers of metastasis. Proc Natl Acad Sci USA 99: 2193-2198, 2002.

59. Makrilia N, Kollias A, Manolopoulos L and Syrigos K: Cell adhesion molecules: Role and clinical significance in cancer. Cancer Invest 27: 1023-1037, 2009.

60. Yashiro M, Sunami T and Hirakawa K: CD54 expression is predictive for lymphatic spread in human gastric carcinoma. Dig Dis Sci 50: 2224-2230, 2005.

61. Maruo Y, Gochi A, Kaihara A, Shimamura H, Yamada T, Tanaka N and Orita K: ICAM-1 expression and the soluble ICAM-1 level for evaluating the metastatic potential of gastric cancer. Int J Cancer 100: 486-490, 2002.

62. Jung WC, Jang YJ, Kim JH, Park SS, Park SH, Kim SJ, Mok YJ and Kim CS: Expression of intercellular adhesion molecule-1 and E-Selectin in gastric cancer and their clinical significance. J Gastric Cancer 12: 140-148, 2012.

63. Hsu NY, Chow KC, Chen WJ, Lin CC, Chou FF and Chen CL: Expression of nm23 in the primary tumor and the metastatic regional lymph nodes of patients with gastric cardiac cancer. Clin Cancer Res 5: 1752-1757, 1999.

64. Kim KM, Lee A, Chae HS and Shim SI: Expression of p53 and NDP-K/nm23 in gastric carcinomas-association with metastasis and clinicopathologic parameters. J Korean Med Sci 10: 406-413, 1995.

65. Yu G, Wang J, Chen Y, Wang X, Pan J, Li Q and Xie K: Tissue microarray analysis reveals strong clinical evidence for a close association between loss of annexin A1 expression and nodal metastasis in gastric cancer. Clin Exp Metastasis 25: 695-702, 2008.

66. Li Y, Wang L, Kang A, Fan L, Zhao Q, Tan B, Hao Y and Liu Q: Screening and identification of proteins related to gastric cancer metastasis with comparative proteomics. Nan Fang Yi Ke Da Xue Xue Bao 35: 360-364, 2015 (In Chinese).

67. Li Y, Tan BB, Zhao Q, Fan LQ, Liu Y and Wang D: Regulatory mechanism of ZNF139 in multi-drug resistance of gastric cancer cells. Mol Biol Rep 41: 3603-3610, 2014.

68. Li Y, Tan BB, Zhao Q, Fan LQ, Wang D and Liu Y: ZNF139 promotes tumor metastasis by increasing migration and invasion in human gastric cancer cells. Neoplasma 61: 291-298, 2014.

69. Ikeda Y, Mori M, Kajiyama K, Haraguchi Y, Sasaki O and Sugimachi K: Immunohistochemical expression of sialyl Tn, sialyl Lewis a, sialyl Lewis $\mathrm{a}-\mathrm{b}-$ and sialyl Lewis $\mathrm{x}$ in primary tumor and metastatic lymph nodes in human gastric cancer. J Surg Oncol 62: 171-176, 1996.

70. Pahujaa M, Anikin M and Goldberg GS: Phosphorylation of connexin43 induced by Src: Regulation of gap junctional communication between transformed cells. Exp Cell Res 313: 4083-4090, 2007.

71. el-Sabban ME and Pauli BU: Adhesion-mediated gap junctional communication between lung-metastatatic cancer cells and endothelium. Invasion Metastasis 14: 164-176, 1994.
72. Tang B, Peng ZH, Yu PW, Yu G and Qian F: Expression and significance of $\mathrm{Cx} 43$ and $\mathrm{E}$-cadherin in gastric cancer and metastatic lymph nodes. Med Oncol 28: 502-508, 2011.

73. Paliouras GN, Naujokas MA and Park M: Pak4, a novel Gab1 binding partner, modulates cell migration and invasion by the Met receptor. Mol Cell Biol 29: 3018-3032, 2009.

74. Gherardi E, Birchmeier W, Birchmeier C and Woude GV: Targeting MET in cancer: Rationale and progress. Nat Rev Cancer 12: 89-103, 2012.

75. Ma J, Ma J, Meng Q, Zhao ZS and Xu WJ: Prognostic value and clinical pathology of MACC-1 and c-MET expression in gastric carcinoma. Pathol Oncol Res 19: 821-832, 2013.

76. Comoglio PM, Giordano S and Trusolino L: Drug development of MET inhibitors: Targeting oncogene addiction and expedience. Nat Rev Drug Discov 7: 504-516, 2008

77. Chan AM, Rubin JS, Bottaro DP, Hirschfield DW, Chedid M and Aaronson SA: Identification of a competitive HGF antagonist encoded by an alternative transcript. Science 254: 1382-1385, 1991.

78. Mihailidou C, Karamouzis MV, Schizas D and Papavassiliou AG: Co-targeting c-Met and DNA double-strand breaks (DSBs): Therapeutic strategies in BRCA-mutated gastric carcinomas. Biochimie 142: 135-143, 2017.

79. Tian M, Yu L, Zhang Y and Gao X: Correlations between SUVmax and expression of GLUT1 and growth factors inducing lymphangiogenesis. Acad Radiol 19: 420-426, 2012.

80. Meng F, Li H, Shi H, Yang Q, Zhang F, Yang Y, Kang L, Zhen T, Dai S, Dong Y and Han A: MACC1 down-regulation inhibits proliferation and tumourigenicity of nasopharyngeal carcinoma cells through Akt/ $\beta$-catenin signaling pathway. PLoS One 8: e60821, 2013

81. Mak H, Naba A, Varma S, Schick C, Day A, SenGupta SK, Arpin M and Elliott BE: Ezrin phosphorylation on tyrosine 477 regulates invasion and metastasis of breast cancer cells. BMC Cancer 12: 82, 2012.

82. Wu B, Li J, Huang D, Wang W, Chen Y, Liao Y, Tang X, Xie H and Tang F: Baicalein mediates inhibition of migration and invasiveness of skin carcinoma through Ezrin in A431 cells. BMC Cancer 11: 527, 2011.

83. Li L, Wang YY, Zhao ZS and Ma J: Ezrin is associated with gastric cancer progression and prognosis. Pathol Oncol Res 17: 909-915, 2011.

84. Jin J, Jin T, Quan M, Piao Y and Lin Z: Ezrin overexpression predicts the poor prognosis of gastric adenocarcinoma. Diagn Pathol 7: 135, 2012.

85. Dong CX, Fu JF, Ye XY, Li XF, Zhong X and Yuan Y: Surgical resection of advanced gastric cancer following trastuzumab/oxaliplatin/capecitabine combination therapy. World J Gastroenterol 20: 12355-12358, 2014.

86. Kim K, Chun KH, Suh PG and Kim IH: Alterations in cell proliferation related gene expressions in gastric cancer. Crit Rev Eukaryot Gene Expr 21: 237-254, 2011.

87. Birchmeier C, Birchmeier W, Gherardi E and Vande Woude GF: Met, metastasis, motility and more. Nat Rev Mol Cell Biol 4: 915-925, 2003.

88. Okines AF, Reynolds AR and Cunningham D: Targeting angiogenesis in esophagogastric adenocarcinoma. Oncologist 16: 844-858, 2011 